\title{
Codetermination and product differentiation
}

\section{Luciano Fanti • Luca Gori • Mauro Sodini}

\begin{abstract}
This research revisits the theoretical literature on codetermination in differentiated Cournot duopoly markets. Although codetermination is widely adopted in some north European countries, the theoretical analysis is restricted to a few number of works. The literature is led by Kraft (1998), who shows that codetermination emerges as a market outcome (sub-optimal Nash equilibrium) in a quantity-setting duopoly with homogeneous products. However, there exists evidence that codetermination is quite absent in countries where there are no specific laws. This article shows that codetermination cannot emerge as a Nash equilibrium when products are sufficiently differentiated (even when they are complementary). These results also holds by considering $\mathrm{R} \& \mathrm{D}$ activities.
\end{abstract}

Keywords Codetermination; Differentiated duopoly; Quantity competition

JEL Classification D43; J53

L. Fanti

Department of Economics and Management, University of Pisa, Via Cosimo Ridolfi, 10, I-56124 Pisa (PI), Italy e-mail: luciano.fanti@unipi.it

tel.: +390502216 369; fax: +390502210603

L. Gori (corresponding author)

Department of Political Science, University of Genoa, Piazzale E. Brignole, 3a, I-16125 Genoa (GE), Italy

e-mail: luca.gori@unige.it or dr. luca.gori@gmail.com tel.: +39010 20995 03; fax: +390102095536

M. Sodini

Department of Economics and Management, University of Pisa, Via Cosimo Ridolfi, 10, I-56124 Pisa (PI), Italy e-mail: mauro.sodinieunipi.it

tel.: +39050 2216 234; fax: +39050 2210603 


\section{Introduction}

Although the theory of bargaining over wages (right-to-manage) or both wages and employment (efficient bargaining) has been widely analysed in recent decades (Booth, 1995), less attention was devoted to the study of bargaining over employment without any wage negotiations. However, this is a relevant feature of the German industry due to codetermination laws at least since the $1950 \mathrm{~s}^{1}$ The institution of codetermination - which implies that employees representatives sit on the supervisory board or similar structures in large companies - is widespread also in other European countries: amongst the 16 countries covered by European Industrial Relations Observatory (EIRO), only the UK stands alone in having no statutory form of board-level representation or significant collectively agreed provisions. ${ }^{2}$ In particular, comprehensive legislation on board-level representation can be found in several influential European countries such as Austria, Denmark, Finland, France, Germany, Luxembourg, the Netherlands, Norway and Sweden. This was extensively discussed in a report of the Eurofound by Schulten and Zagelmeyer (1998) as well as in the recent book of Waddington and Conchon (2016). Moreover, with regard to the political debate in Europe, an active worker involvement may be considered as a crucial element of the European social model, particularly suited to meet the increasing social and economic challenges. ${ }^{3}$ Despite this fact, the economic analysis on the effects of codetermination is little and this constitutes a gap on the side of policy recipes at the European level: "The practice of board participation and its

\footnotetext{
1 Recently, codetermination rules have been extended in Germany and are high on the political agenda in other European countries (see the discussion in Kraft, 2001). Moreover, bargaining over employment is not restricted to the case of codetermination laws. Indeed, it may be applied whenever either employment is determined at the firm level (with centralised unions that negotiate over wages) or when the length of wage contracts is larger than the length needed to employment adjustments.

2 Although in countries such as Belgium and Italy there is no general legislation or widely applicable collective agreements providing for board-level representation, there exist specific provisions for board-level employee representatives in some public companies (e.g., the state railway in Belgium and a number of state holding companies in Italy).

${ }^{3}$ The institution of co-determination has been high also on the political debate of the European Commission. In this regard, the Davignon report (published on October 27 $7^{\text {th }}$ 1970) in the section that focused on the "European systems of worker involvement", accounting for the national diversity of worker participation in Europe, stated that: "Globalisation of the economy and the special place of European industry raises fundamental questions regarding the power of social partners within the company. The type of labour needed by European companies - skilled, mobile, committed, responsible, and capable of using technical innovations... cannot be expected simply to obey the employers' instructions. Workers must be closely and permanently involved in decision-making at all levels of the company." (Schulten and Zagelmeyer, 1998).
} 
impact are very hard to gauge, given a general lack of research and evidence.” (Schulten and Zagelmeyer, 1998).

On theoretical grounds, one of the first work that tried to set up a consistent framework on the issue of codetermination was McCain (1980), who had the merit of clarifying the problem of determining labour productivity and working conditions by using a noncooperative game approach to compare several representations of workers' interests. The literature was then carried on by the contribution of Kraft (1998), who investigated a Cournot duopoly with homogenous products showing that profit maximising firms have an incentive to become bargainers over employment without any law enforcement. This in turn implies that codetermination results to be the dominant (but Pareto inefficient) strategy in a game played by firms that have to choose between profit maximisation and codetermination. Although this result was little emphasised in the academic and political debates, it would have far-reaching theoretical consequences. In particular,

1) Codetermination emerges as the endogenous outcome of a strategic competitive framework (duopoly) with quantity-setting firms, thus coming not only from legislative rules.

2) Codetermined firms have an advantage in terms of profits and market shares when competing with profit-maximising rivals. Thus, one could argue that codetermination may be one of the reasons why German (codetermined) firms often perform better than their international profitmaximising counterparts may. In fact, under codetermination output is higher than under profit maximisation. This implies that consumers and the society as a whole are better off, as is stressed by Kraft (1998, p. 200): “This comparison has the surprising result that codetermination is welfare maximizing!"

Other works on codetermination belonging to the industrial organisation literature later followed. In this regard, Kraft (2001) extended his previous work by accounting for a general oligopolistic market and discussed the effects of employment bargaining from both theoretical and empirical 
perspectives. In the theoretical setting, he confirmed the existence of a prisoner's dilemma for a range of bargaining power. Then, he also tested whether codetermination leads to increased profits in large German firms if rivals are traditional profit maximisers. The findings are "The higher profits are a result of the tendency of the codetermined firms to be larger than their competitors. However a specific effect on the relation between the market share and the price cost margin is derived here. The market share of a codetermined firm is expected to have a smaller effect on the price cost margin compared to conventional companies. However because of the size effect of codetermination the market share is larger. The two opposing effects on the price cost margin have just the same magnitude and thus in the end the codetermined firm has the usual price cost margin... Codetermined firms show a different behavior than others, but the effect is not always significant. At least it seems fair to say that the 'surprise' from the theoretical section is not refused by the empirical results." (Kraft, 2001, p. 563). Two other contributions concentrate on the relationship between codetermination and $R \& D$ activities. The former is Granero (2006) who built on a quantity setting duopoly by assumed that the objective function of the firm/manager is a weighted sum of profits and the income paid to workers, where the relative proportions of board votes of shareholders and workers represent the weight of the problem. Results implied that codetermination could help a firm to increase the market share, employment and innovativity. The latter is Kraft et al. (2011) who took Kraft $(1998,2001)$ as a starting point and studied the effects of the German Codetermination Act of 1976 on the innovative activity of German firms. ${ }^{4}$ The authors proposed a duopoly model by (exogenously) comparing profits and $R \& D$ innovative activity under codetermination and profit maximisation by assuming that $R \& D$ was not the subject of negotiations. On empirical grounds, their results "do not support the view that co-determination slows down technological progress and reduces innovativity" (Kraft et al., 2011, p. 145) by taking the number of patents as a benchmark. Fanti and Gori (2012) considered a Kraft-like economy, but mainly focusing on the stability effects of codetermination in a context of bounded rationality.

\footnotetext{
4 This law introduced the possibility of equal representation of employers and employees' representative on the supervisory board of large companies.
} 
Amongst other things, they found that the relative size of the union power in the Nash bargaining matters for the stability of the Nash equilibrium in the long term. Finally, Gürtler and Höffler (2015) studied the role of works councils on the monitoring of workers. By starting from the (stylised) fact that workers protection in the European Union is stronger than in the US (by stressing the role played by works councils in German codetermined large companies), ${ }^{5}$ the authors highlighted the existence of a puzzle in the behaviour of firm owners when their control rights on the monitoring of workers are reducing. The main aim of their work was then to build on a theoretical framework to resolve the puzzle. By considering a model with two competing firms that may install a monitoring technology, they found that consumers are actually those who pay the bill because of the reduced competition amongst firms (with the resulting reduction in output and increase in market price) and the increased profits. This is because of the information rent that can be extracted through the works councils that may help workers behaving in agreement with owners or shareholders.

On the strict side of the empirical evidence, the story is much longer but many authors argue that the economic effects of codetermination were not adequately taken into account. ${ }^{6}$ Amongst a few, we mention the works of Cable and FitzRoy (1980) that found positive effects of codetermination on labour productivity by estimating a Cobb-Douglas production function for 42 large German companies, and the work of FitzRoy and Kraft (1993) that took into account data for 68 German coal and steel firms by comparing two years before (1975) and after (1983) the introduction the codetermination act of 1976. In contrast to Cable and FitzRoy (1980), they found that codetermination contributes to reduce labour productivity by also favouring a decline in the return on equity. Subsequently, Baums and Frick (1998) analysed the impact of court decisions about codetermination laws for the period 1974-1995 finding no statistically significant stock market

\footnotetext{
5 "Within the system of "co-determination" works councils have legally guaranteed influence on management decisions concerning working conditions within a firm. For instance, the law prescribes that worker representatives must consent to any introduction of technologies that monitor the workers' effort and output." (Gürtler and Höffler, 2015, p. 1366).

6 This was noted first by FitzRoy and Kraft (1993, p. 366) "there have been few attempts to quantify economic effects, and they all suffer from inadequate data and methodology" and then by Gorton and Schmid (2004, p. 867) "There is relatively little quantitative work on the effects of codetermination at the supervisory board level".
} 
response to the court verdicts. Later, Gorton and Schmid (2004) in an influential work concluded for a negative effect of codetermination on the market value of firms by taking annual observations for the period 1989-1993 of 250 German nonfinancial stock corporations and comparing firms near parity (i.e., equal representation of employees and shareholders on the supervisory board) with firms where employee representation is lower (one-third). Finally, through the study of panel estimates of codetermination, FitzRoy and Kraft (2005) concluded for a positive labour productivity effect of near parity codetermination.

The empirics on codetermination is therefore controversial, though it seems to prevail a negative effect of the codetermination laws on the performance of firms (productivity, market value, etc.), which is in line with the negative effect on profits found in the existing theoretical literature and confirmed in the present work.

The aim of this article is to revisit the theoretical literature on codetermination led by the quantity-setting duopoly with homogenous product of Kraft (1998) and subsequently extended by Kraft et al. (2011) to account for product differentiation and R\&D activities but without investigating endogenous firms' choices. However, it is a stylised fact that duopoly markets often work under product differentiation (as is also reported in Kraft et al., 2011). Therefore, it is natural to wonder about the robustness of the emergence of codetermination as a market (Nash equilibrium) outcome under the special assumption of homogenous products due to the practical unobservable emergence of codetermination without a law enforcement. This article went through this direction by making the firm's choice to be codetermined or profit maximiser endogenous also under product differentiation as well as in the R\&D-like economy à la Kraft et al. (2011), where only an exogenous comparison amongst equilibrium outcomes of codetermined and profitmaximising firms in terms of profits and $R \& D$ investments was reported. The main finding is that the results of Kraft (1998) may not be robust to a more general setting including horizontal product differentiation (Singh and Vives, 1984). More in general, it results that codetermination do not 
emerge as a market outcome in a strategic competitive framework with and without R\&D investment if product are perceived as being differentiated by customers.

Under codetermination, employees have a role in the governance of a firm. Two typical and opposite situations that may be useful to clarify the effects of codetermination laws through collective agreements are those regarding the role of employees in US and Germany. In the former country, workers are not engaged in corporate management (this holds in a socio-economic context where the power of union is steadily declining and competitive market pressures is steadily increasing). In the latter, instead, they are engaged in corporate management even with relevant responsibilities in boards of directors and management and workers' committees (this has represented the standard social market economy point of view of North European countries that has historically contrasted the Anglo-American one). Indeed, as Kraft states (1998, p. 195) the decision with regard to "employment determination are handled by the supervisory board in codetermined firms. On the supervisory board, employees have near-parity rights. In the iron and steel industry as well as in mining employees have explicit parity decision rights." The case of near-parity represents, therefore, a specific case of German codetermination within a wider range of distinct bargaining powers between each union and firm bargain unit in determining employment. ${ }^{7}$ Under these circumstances, Kraft (1998) shows that codetermination emerges as the endogenous choice of firms that compete strategically in a quantity-setting duopoly with homogeneous products, and each codetermined firm has a competitive advantage with respect to the profit-maximising rival. Our findings obtained by adding product differentiation to Kraft (1998) dramatically contrast Kraft's ones. Specifically, even a relatively small degree of product differentiation represents a sufficient ingredient allows avoiding the emergence of codetermination as a sub-game perfect Nash equilibrium (SPNE, henceforth) of the game. In fact, as far as the degree of substitutability reduces (i.e., products are perceived as being increasingly differentiated by customers), each firm wants to

\footnotetext{
7 To avoid confusion, we clarify here that we use the terms "unions" and "employees' or workers' committees" as synonyms throughout the article though in general they have different meanings. However, as codetermination implies the existence of committees of representatives that protect the interests of employees (that may also potentially be nonunionised) within the firm, their behaviour is quite similar to that of the unions.
} 
gain through product market differentiation that in turn reduces the unilateral introduction of codetermination. Then, product differentiation tends to make unprofitable the choice of being a codetermined firm. ${ }^{8}$

These results deserve some additional considerations. If products are quasi-homogeneous the fact that legislation dictates (with the aim of enhancing social welfare) firms to be codetermined could be redundant, as firms should choose endogenously codetermination (as argued by Kraft, 1998). However, it is observed in practice that codetermination exists only whether the lawmaker enforces the institution: this may be explained by postulating, for instance, a tacit cooperative agreement between firms to do not apply codetermination (for instance, under the "ideology" that the owner should be free to manage his own firm). ${ }^{9}$ Results, however, show that the actual feature of a ubiquitous product differentiation may constitute a purely "economic" explanation. Indeed, if products are differentiated (even a little bit when unions are sufficiently strong) firms would have no convenience to deviate towards codetermination. The main outcomes of this work are confirmed in the model extended to $R \& D$ activities.

The rest of the article proceeds as follows. Section 2 sets up a Cournot differentiated duopoly à la Kraft (1998) and then contrasts the behaviours of firms that have to choose to be bargainers under codetermination or profit maximisers. Section 3 tackles the issue of choosing to be codetermined or profit maximiser from the firm point of view in a context à la Kraft et al. (2011) with product differentiation and R\&D activities. Section 4 outlines the conclusions.

\section{Codetermination and product differentiation in a Cournot duopoly}

Both firms produce according to a standard production function with constant returns to labour. Formally, this implies that short-period output is produced by employing the technology $q_{i}=L_{i}$,

\footnotetext{
${ }^{8}$ By contrast, if products are complementary codetermination may be more or less profitable depending on the degree of complementarity and the union's power.

${ }^{9}$ Notice that dictating codetermination rules in one country may potentially bring about an advantage in terms of market shares (and profits) for codetermined firms (as compared with profit maximising rivals in other countries). Then, it remains an empirical question whether codetermination may effectively explain the successful performances of German firms in markets where there is quantity competition and product homogeneity.
} 
where $L_{i}$ represents the labour force hired in firm $i, i=\{1,2\}$, implying that one unit of labour is transformed into one unit of output (Correa-López and Naylor, 2004; Fanti et al., 2017). Firm $i$ faces a marginal (and average) cost $0 \leq w_{i}<1$, where $w_{i}$ is per-worker wage per unit of labour, which is exogenously fixed for each single firm, as it is set in a centralised bargaining. Therefore, firm $i$ 's cost function is linear and given by:

$$
C_{i}=w_{i} L_{i}=w_{i} q_{i}
$$

By assuming the usual quadratic utility specification for representative consumer's preferences augmented with differentiated products à la Singh and Vives (1984), the normalised linear inverse demand of firm $i$ reads as follows:

$$
p_{i}=1-q_{i}-d q_{j}
$$

where $p_{i} \geq 0$ is the marginal willingness to pay of consumers of product $i$ and $q_{i} \geq 0$ represents the quantity produced by firm $i, i, j=\{1,2\}, i \neq j)$. Parameter $-1<d<1$ represents the degree of product differentiation as perceived by firms' customers. More precisely, products of variety $i$ and variety $j$ are perceived to be imperfect substitutes (resp. imperfect complements) if $d>0$ (resp. $d<0$ ), whereas they tend to be perfect substitutes (resp. perfect complements) when $d \rightarrow 1$ (resp. $d \rightarrow-1$ ). If $d \rightarrow 0$, products to be independent and each firm behaves as if it were a monopolist in its own market.

In what follows, we will consider a quantity-setting duopoly where each firm has to choose whether or not adopting codetermination when products are differentiated. As product differentiation directly affects profits of oligopoly firms, the choice between profit maximisation and bargaining under codetermination may be relevant in an oligopoly industry.

Definitely, the timing of the events of this two-stage endogenous game with observable actions is detailed as follows. At stage 1 (the codetermination stage), each owner has to choose to be either a codetermined or profit maximisation firm. At stage 2 (the bargaining market stage), firms either choose output in the case of profit maximisation or bargain over employment together with unions 
in the case of codetermination. We proceed into the analysis according to the standard backward logic.

Profits of firm $i$ are given by

$$
\Pi_{i}=\left(1-w_{i}-q_{i}-d q_{j}\right) q_{i}
$$

Codetermination implies that firms' representatives bargain with employees' representatives over employment but not over wages on the supervisory board, i.e. the wage is determined at a centralised or economy-wide level. The model is outlined in accordance with Kraft (1998). The objective of every firm is to maximise profit $\left(\Pi_{i}\right)$ with respect to employment, whereas the objective of every union is to maximise utility $U_{i}\left(w, L_{i}\right)=\left(w-w^{\circ}\right)^{\theta} L_{i}$ with respect to employment, where $\theta>0$ is the relative weight attached by unions to wages and $w^{\circ}$ is the reservation or competitive wage. Without loss of generality, we set $\theta=1$ and $w^{\circ}=0$ henceforth. We assume that both firms codetermine employment with firm-specific unions. As the production function takes the usual form $q_{i}=L_{i}$, the Nash bargaining between each firm and union bargain unit over employment takes the form:

$$
V_{i}=\left[\left(1-q_{i}-d q_{j}-w\right) q_{i}\right]^{\beta}\left(w q_{i}\right)^{1-\beta},
$$

where the control variable is $q_{i}, 0<\beta \leq 1$ is the relative bargaining power of firm $i$ and $w_{i}=w$ for any firm $i=\{1,2\}$ without loss of generality. Following Kraft (1998) and the literature cited therein, the threat points have been set to zero. Although it may be natural to assume an equal bargaining power between owners and unions (near-parity), $\beta$ close to 0.5 , as employment behaviours in codetermined firms are taken by a supervisory board that is made up in similar quotas by employers and employees delegates, we study the general case $0<\beta \leq 1$ throughout the article to give much deeper theoretical outcomes. Then, we will give specific insights for the parametric cases that capture in a better way the specifics of codetermination.

From (4), the best reply function of firm $i$ (when every firm is codetermined) is given by: 


$$
\frac{\partial V_{i}}{\partial q_{i}}=0 \Leftrightarrow q_{i}\left(q_{j}\right)=\frac{1-d q_{j}-w}{1+\beta}
$$

for $i, j=\{1,2\}, i \neq j$. By using Eq. (5) together with the corresponding counterpart of product of variety $j$, which contribute to define a system of reaction functions when each firm is codetermined (B), we obtain equilibrium output of firm 1 and firm 2, whose values are summarised in Table 1. The standard case of profit maximisation (PM) can be obtained by setting $\beta$ for both firms.

Differently, if firms have mixed behaviours so that firm 1 is codetermined (B) and firm 2 is a profit maximiser (PM), the maximisation of the Nash product for firm $1\left(V_{1}\right)$ and profit for firm 2 $\left(\Pi_{2}\right)$ allows to get the following system of output reaction functions:

$$
\frac{\partial V_{1}}{\partial q_{1}}=0 \Leftrightarrow q_{1}\left(q_{2}\right)=\frac{1-d q_{2}-w}{1+\beta}
$$

and

$$
\frac{\partial \Pi_{2}}{\partial q_{2}}=0 \Leftrightarrow q_{2}\left(q_{1}\right)=\frac{1-d q_{1}-w}{2} .
$$

As $\beta \leq 1$, from (6) and (7) it is clear that the production of codetermined firm 1 is larger than the production of the profit-maximising rival. This is because of the bargaining power of the union, whose objective is to increase employment and output. By solving the system given by (6) and (7) we obtain the output produced by firm 1 and firm 2, respectively:

$$
q_{1}=\frac{(2-d)(1-w)}{2-d^{2}+2 \beta}
$$

and

$$
q_{2}=\frac{(1-d+\beta)(1-w)}{2-d^{2}+2 \beta}
$$

Straightforward algebra allows us to obtain the equilibrium outcomes of the game. Table 1 summarises the quantity produced under profit maximisation and codetermination, whereas Table 2 represents the payoff matrix that contrasts the main findings of profit maximising and codetermined 
firms with product differentiation under quantity competition. ${ }^{10}$ As a matter of notation, in what follows the term PM is referred to profit maximisation as opposed to $\mathrm{B}$, which refers to the case of bargaining under codetermination rules.

\begin{tabular}{|c|c|c|}
\hline Firm 2 & PM & B \\
\hline Firm 1 & & \\
\hline PM & $\frac{1}{2+d}, \frac{1}{2+d}$ & $\frac{1-d+\beta}{2-d^{2}+2 \beta}, \frac{2-d}{2-d^{2}+2 \beta}$ \\
\hline B & $\frac{2-d}{2-d^{2}+2 \beta}, \frac{1-d+\beta}{2-d^{2}+2 \beta}$ & $\frac{1}{1+d+\beta}, \frac{1}{1+d+\beta}$ \\
\hline
\end{tabular}

Table 1. Equilibrium values of quantities of quantity-setting firms in a differentiated duopoly with (B) and without (PM) codetermination.

\begin{tabular}{|c|c|c|}
\hline Firm 2 & PM & B \\
\hline Firm 1 & $\frac{1}{(2+d)^{2}}, \frac{1}{(2+d)^{2}}$ & $\frac{(1-d+\beta)^{2}}{\left(2-d^{2}+2 \beta\right)^{2}}, \frac{\beta(2-d)^{2}}{\left(2-d^{2}+2 \beta\right)^{2}}$ \\
\hline B & $\frac{\beta(2-d)^{2}}{\left(2-d^{2}+2 \beta\right)^{2}}, \frac{(1-d+\beta)^{2}}{\left(2-d^{2}+2 \beta\right)^{2}}$ & $\frac{\beta}{(1+d+\beta)^{2}}, \frac{\beta}{(1+d+\beta)^{2}}$ \\
\hline
\end{tabular}

Table 2. Payoff matrix: profits of quantity-setting firms in a differentiated duopoly with (B) and without (PM) codetermination.

Before inquiring about the endogenous outcome of the game, it is useful to know the transmission mechanisms of a change in the bargaining parameter $\beta$ on profits. For doing this, let us first rewrite the profit functions of firm $i$ when each firm is codetermined $\left(\Pi_{i}^{B / B}\right)$ in the following generic form:

$$
\Pi_{i}^{B / B}=\Pi_{i}^{B / B}\left\{p\left[q_{i}(\beta), q_{j}(\beta)\right], q_{i}(\beta)\right\}
$$

whereas when firm 1 is codetermined $\left(\Pi_{1}^{B / P M}\right)$ and firm 2 is profit-maximising $\left(\Pi_{2}^{B / P M}\right)$ their own generic profit functions are respectively given by:

$$
\Pi_{1}^{B / P M}=\Pi_{1}^{B / P M}\left\{p\left[q_{1}(\beta), q_{2}(\beta)\right], q_{1}(\beta)\right\}
$$

\footnotetext{
${ }^{10}$ Note that the equilibrium values of output (resp. profits) reported in Table 1 (resp. Table 2) are net of the common term $1-w$ (resp. $(1-w)^{2}$ ). This holds also for the model of Section 3 dealing with codetermination and innovation.
} 
and

$$
\Pi_{2}^{B / P M}=\Pi_{2}^{B / P M}\left\{p\left[q_{1}(\beta), q_{2}(\beta)\right], q_{2}(\beta)\right\}
$$

The total derivatives with respect to $\beta$ are the following:

$$
\begin{aligned}
& \frac{d \Pi_{i}^{B / B}}{d \beta}=\overbrace{\frac{\partial \Pi_{i}^{B / B}}{\partial p}}^{+} \cdot(\overbrace{\frac{\partial p}{\partial q_{i}}}^{\bar{i}} \cdot \overbrace{\frac{\partial q_{i}}{\partial \beta}}^{\bar{i}}+\overbrace{\frac{\partial p}{\partial q_{j}}}^{-} \cdot \overbrace{\frac{\partial q_{j}}{\partial \beta}}^{-})+\overbrace{\frac{\partial \Pi_{i}^{B / B}}{\partial q_{i}}}^{+} \cdot \overbrace{\frac{\partial q_{i}}{\partial \beta}}^{\bar{\sim}}, \\
& \frac{d \Pi_{1}^{B / P M}}{d \beta}=\overbrace{\frac{\partial \Pi_{1}^{B / P M}}{\partial p}}^{+} \cdot(\overbrace{\frac{\partial p}{\partial q_{1}}}^{=} \cdot \overbrace{\frac{\partial q_{1}}{\partial \beta}}^{z}+\overbrace{\frac{\partial p}{\partial q_{2}}}^{-} \cdot \overbrace{\frac{\partial q_{2}}{\partial \beta}}^{+})+\overbrace{\frac{\partial \Pi_{1}^{B / P M}}{\partial q_{1}}}^{+} \cdot \overbrace{\frac{\partial q_{1}}{\partial \beta}}^{-},
\end{aligned}
$$

and

$$
\frac{d \Pi_{2}^{B / P M}}{d \beta}=\overbrace{\frac{\partial \Pi_{2}^{B / P M}}{\partial p}}^{+} \cdot(\overbrace{\frac{\partial p}{\partial q_{1}}}^{-} \cdot \overbrace{\frac{\partial q_{1}}{\partial \beta}}^{-}+\overbrace{\frac{\partial p}{\partial q_{2}}}^{-} \cdot \overbrace{\frac{\partial q_{2}}{\partial \beta}}^{+})+\overbrace{\frac{\partial \Pi_{2}^{B / P M}}{\partial q_{2}}}^{+} \cdot \overbrace{\frac{\partial q_{2}}{\partial \beta}}^{+},
$$

The outcome of a change in $\beta$ on profits passes through the usual effects on price (indirect effect) and quantity (direct effect). As can be seen by looking at the entries of Table 2 (payoff matrix), an increase in the union's bargaining power (a reduction in $\beta$ ) causes a reduction in profits of firm 1 and firm 2 when both firms are codetermined $\left(\partial \Pi_{i}^{B / B} / \partial \beta>0\right)$ and a reduction in profits of the noncodetermined firm 2 when the rival is codetermined $\left(\partial \Pi_{2}^{B / P M} / \partial \beta>0\right)$. Differently, the sign of $\partial \Pi_{1}^{B / P M} / \partial \beta$ depends on the size of $\beta$. The reasons for these outcomes are the following. With regard to $\Pi_{i}^{B / B}$, a reduction in $\beta$ causes an increase in production of both firms (because employment tends to increase) that in turn implies an increase in profits. As the quantity of firm $i$ and firm $j$ increase when $\beta$ reduces, the market price goes down (the demand is negatively sloped) and then profits reduce through this channel. Knowing that $\partial \Pi_{i}^{B / B} / \partial \beta>0$, we may conclude that the effect of the reduction in market price more than offsets the effect of the increase in production. This is the reason why a reduction in $\beta$ reduces profits when both firms are codetermined. In contrast, when only firm 1 is codetermined, the outcome of a reduction in $\beta$ on $\Pi_{1}^{B / P M}$ follows a 
twofold effect. First, when $\beta$ reduces we observe an increase in production and profit of firm 1. The price effect, however, is ambiguous as the quantity produced by the non-codetermined firm 2 reduces when $\beta$ increases. In the case $\beta$ is sufficiently large (i.e., the bargaining power of the union is small), we observe that a reduction in $\beta$ increases $\Pi_{1}^{B / P M}$. This means that irrespective of the sign of the price effect, the direct effect due to the increase in production dominates and then profits increase. In the case $\beta$ is sufficiently small (i.e., the bargaining power of the union is large), a reduction in $\beta$ reduces $\Pi_{1}^{B / P M}$. This implies that the price effect is negative and its size is larger than the positive effect on quantity. With regard to the non-codetermined firm 2 , we have that a reduction in $\beta$ causes a reduction in $\Pi_{2}^{B / P M}$. This is because the quantity produced by firm 2 reduces. This direct effect dominates irrespective of the sign of the price effect.

Let us now turn on the analysis of the specific case of linear demand analysed above by stating the following lemma.

Lemma 1. If products are substitutes $(0<d \leq 1)$, profits of the profit-maximising firm are larger than profits of the codetermined firm. A reduction in $\beta$ (i.e., an increase in the union's bargaining power) monotonically reduces $\Pi_{i}^{B / B}$.

Proof. The proof can be obtained by comparing $\Pi_{i}^{P M / P M}$ with $\Pi_{i}^{B / B}$ and knowing that $\frac{\partial \Pi_{i}^{B / B}}{\partial \beta}=\frac{(1+d-\beta)(1-w)^{2}}{(1+d+\beta)^{3}}>0$. Q.E.D.

Now, let $\beta_{a}(d):=\frac{\left(2-d^{2}\right)^{2}}{4}>0$ for any $-1 \leq d \leq 1, \quad \beta_{b}(d):=\frac{\mathrm{M}^{2 / 3}-2 \mathrm{M}^{1 / 3}-24 d^{2}+16}{6 \mathrm{M}^{1 / 3}}>0$, for any $-1 \leq d \leq 1$ and $\beta_{c}(d):=(1+d)^{2}>0$ for any $-1 \leq d \leq 0$ be three threshold values of $\beta$ such that profit 
differentials $\Delta_{a}=\Pi_{i}^{B / P M}-\Pi_{i}^{P M / P M}=0, \Delta_{b}=\Pi_{i}^{P M / B}-\Pi_{i}^{B / B}=0$ and $\Delta_{c}=\Pi_{i}^{P M / P M}-\Pi_{i}^{B / B}=0$, respectively, where

$$
\mathrm{M}:=108 d^{4}-144 d^{2}+12 \sqrt{3} d^{2} \sqrt{27 d^{4}-40 d^{2}+16}+64 .
$$

The shape of the threshold values $\beta_{a}(d), \beta_{b}(d)$ and $\beta_{c}(d)$ is clear and depicted in Figure 1 in the parameter space $(\beta, d)$. Then, the following proposition holds.

Proposition 1. [Codetermination and product differentiation]. (a) (Product substitutability, $0<d \leq 1)$. (1) If $1>\beta>\beta_{a}(d)$ then $(\mathrm{B}, \mathrm{B})$ is the unique Pareto inefficient SPNE of the game (prisoner's dilemma). (2) If $\beta_{a}(d)>\beta>\beta_{b}(d)$ then there exist two pure-strategy Nash equilibria given by (B,B) and (PM,PM), and PM payoff dominates $\mathrm{B}$ (coordination game). (3) If $\beta_{b}(d)>\beta>0$ then (PM,PM) is the unique Pareto efficient SPNE of the game (cooperation game).

(b) (Product complementarity, $-1 \leq d \leq 0)$. (1) If $1>\beta>\beta_{a}(d)$ then $(\mathrm{B}, \mathrm{B})$ is the unique Pareto efficient SPNE of the game (cooperation game). (2) If $\beta_{a}(d)>\beta>\beta_{b}(d)$ then there exist two purestrategy Nash equilibria given by (B,B) and (PM,PM), and B payoff dominates PM (coordination game). (3) If $\beta_{b}(d)>\beta>\beta_{c}(d)$ then (PM,PM) is the unique Pareto inefficient SPNE of the game (prisoner's dilemma). (4) If $\beta_{c}(d)>\beta>0$ then (PM,PM) is the unique Pareto efficient SPNE of the game (cooperation game). ${ }^{11}$

Proof. The profit differentials are the following:

$$
\Delta_{a}=\frac{(1-w)^{2}(1-\beta)\left[4 \beta-\left(2-d^{2}\right)^{2}\right]}{(2+d)^{2}\left(2-d^{2}+2 \beta\right)^{2}}
$$

\footnotetext{
${ }^{11}$ Under price competition, the unique SPNE is (PM,PM) in both cases of product substitutability (prices are strategic complements) and complementarity (prices are strategic substitutes). This implies that $(\mathrm{B}, \mathrm{B})$ does never emerge as a market outcome under Bertrand rivalry. We do not include a formal treatment of a price competition model in this article, but the analysis is available on request.
} 


$$
\Delta_{b}=\frac{(1-w)^{2}(1-\beta)\left[-\beta^{3}-\beta^{2}+\beta\left(1-2 d^{2}\right)+\left(1-d^{2}\right)^{2}\right]}{\left(2-d^{2}+2 \beta\right)^{2}(1+d+\beta)^{2}},
$$

and

$$
\Delta_{c}=\frac{(1-w)^{2}(1-\beta)\left[(1+d)^{2}-\beta\right]}{(2+d)^{2}(1+d+\beta)^{2}} .
$$

The sign of $\Delta_{a}, \Delta_{b}$ and $\Delta_{c}$ change depending on the relative position of $\beta$ and $d$. In the case of product substitutability $(0<d \leq 1), \Delta_{c}>0$ for any $0<\beta<1$ (Lemma 1 ), and (1) if $1>\beta>\beta_{a}(d)$ then $\Delta_{a}>0$ and $\Delta_{b}<0,(2)$ if $\beta_{a}(d)>\beta>\beta_{b}(d)$ then $\Delta_{a}<0$ and $\Delta_{b}<0$, (3) if $\beta_{b}(d)>\beta>0$ then $\Delta_{a}<0$ and $\Delta_{b}>0$. Therefore, point (a) follows. In the case of product complementarity $(-1 \leq d \leq 0)$, we have that (1) if $1>\beta>\beta_{a}(d)$ then $\Delta_{a}>0, \Delta_{b}<0$ and $\Delta_{c}<0$, (2) if $\beta_{a}(d)>\beta>\beta_{b}(d)$ then $\Delta_{a}<0$, $\Delta_{b}<0$ and $\Delta_{c}<0$, (3) if $\beta_{b}(d)>\beta>\beta_{c}(d)$ then $\Delta_{a}<0, \Delta_{b}>0$ and $\Delta_{c}<0$, (4) if $\beta_{c}(d)>\beta>0$ then $\Delta_{a}<0, \Delta_{b}>0$ and $\Delta_{c}>0$. Therefore, point (b) follows. Q.E.D.

Corollary 1. [Codetermination and product differentiation]. (Homogeneous products, $d=1$ ). (1) If $1>\beta>\beta_{a}(d)=0.25$ then $(\mathrm{B}, \mathrm{B})$ is the unique Pareto inefficient SPNE of the game (prisoner's dilemma of Kraft, 1998). (2) If $0.25=\beta_{a}(d)>\beta>0$ then there exist two pure-strategy Nash equilibria given by $(\mathrm{B}, \mathrm{B})$ and $(\mathrm{PM}, \mathrm{PM})$, and PM payoff dominates B (coordination game).

Proof. If $d=1$ then $\Delta_{a}=\frac{(1-w)^{2}(1-\beta)(4 \beta-1)}{9(1+2 \beta)^{2}}, \Delta_{b}=\frac{-(1-w)^{2}(1-\beta)\left(\beta^{3}+\beta^{2}+\beta\right)}{(2+\beta)^{2}(1+2 \beta)^{2}}<0 \quad$ and $\Delta_{c}=\frac{(1-w)^{2}(1-\beta)(4-\beta)}{9(2+\beta)^{2}}>0$. (1) If $1>\beta>\beta_{a}(d)=0.25$ then $\Delta_{a}>0, \Delta_{b}<0$ and $\Delta_{c}>0$. (2) If $0.25=\beta_{a}(d)>\beta>0$ then $\Delta_{a}<0, \Delta_{b}<0$ and $\Delta_{c}>0$. Q.E.D.

Proposition 1 shows the existence of a wide spectrum of equilibrium outcomes in a codetermination game with product differentiation in either cases of substitutability and complementarity. We 
restrict the discussion to the case of product substitutability (the case of complementarity is quite similar). The result of Kraft (1998) holds only when the unions' bargaining power is sufficiently small (i.e., $\beta$ is relatively high), i.e. when owners' profits weight relatively more than union's utility in the Nash product given by Eq. (4), and it is relegated to a relatively small area in $(\beta, d)$ space. In fact, in this case, for each player B strictly dominates PM, so that every firm wants to be subject to codetermination. However, there exists an incentive for firms to coordinate themselves to play profit maximisation, but no one has a unilateral incentive to deviate from B (prisoner's dilemma). When $\beta$ reduces (i.e., the union's bargaining power increases), there exist multiple equilibria in pure strategies. Firms want to maximise their own profits and unions want to maximise their own utilities. In doing this, production tend to increase when the bargaining power of firms reduces. In this case, no dominated strategies do exist because $\Pi_{1}^{B / P M}$ reduces when $\beta$ goes down until a point at which $\Pi_{1}^{B / P M}$ becomes lower than $\Pi_{1}^{P M / P M}$. The consequence is that there is no more a unilateral incentive for each player to deviate from PM. As multiple pure-strategy Nash equilibria exist in this case, from a prisoner's dilemma the game becomes a standard coordination game. Then, it may be useful to adopt a criterion to select equilibria. To this purpose, we introduce mixed strategies and show that a (unique) mixed-strategy Nash equilibrium does actually exist. To proceed further, we consider that a Nash equilibrium in mixed strategies can be obtained by defining probabilities $x_{1}$ and $1-x_{1}$ (resp. $x_{2}$ and $1-x_{2}$ ) that firm 1 (resp. firm 2) plays either B or PM. Therefore, we find that a mixed-strategy Nash equilibrium is given by:

$$
\begin{aligned}
& x_{1}=x_{2}=x_{*}^{B / P M}=\frac{\prod_{i}^{B / P M}-\Pi_{i}^{P M / P M}}{\left(\Pi_{i}^{B / P M}-\prod_{i}^{P M / P M}\right)+\left(\Pi_{i}^{P M / B}-\Pi_{i}^{B / B}\right)}= \\
& =\frac{(1+d+\beta)^{2}\left[\left(2-d^{2}\right)^{2}-4 \beta\right]}{d(1-\beta)\left[4+7 d+2 d \beta-4 \beta^{2}-5 d^{3}-d \beta^{2}-2 d^{4}-d^{3} \beta\right]}
\end{aligned}
$$

From (10) it is easy to check that $x_{*}^{B / P M}>0$ only when $\beta_{a}(d)>\beta>\beta_{b}(d)$ and it is a decreasing function of $\beta$. This probability vanishes when $\beta=\beta_{a}(d)$ and approaches 1 when $\beta \rightarrow \beta_{b}(d)$. This behaviour is in line with the results summarised in Proposition 1, Point (a). In fact, for $\beta>\beta_{a}(d)$ 
there exists only one (sub-optimal) Nash equilibrium and the game boils down to the standard prisoner's dilemma found by Kraft (1998), whereas for $\beta<\beta_{b}(d)$ (PM,PM) is the Pareto efficient SPNE, thus contrasting the Kraft's result under quantity competition and product substitutability. In this case, no codetermination emerges at all and the prisoner's dilemma is solved. The rule that comes from the mixed-strategy Nash equilibrium expression in (10) is therefore the following: each firm will choose to play B (resp. PM) as a pure strategy if the rival plays B (resp. PM) with a probability $x>x_{*}^{B / P M}$ (resp. $x<x_{*}^{B / P M}$ ). The lower $\beta$, the higher the probability of playing PM as a pure strategy. We note that the case of multiple equilibria (emerging for an opportune $\beta$ - $d$ pairs), which is depicted in Figure 1 for both the case of product substitutability (region B) and complementarity (region F), can be investigated more in detail by resorting to well-known criteria of Pareto-dominance and Risk-dominance for equilibrium selection. ${ }^{12}$ However, for the sake of simplicity, we limit ourselves to point out whether and how Pareto-dominance appears. This is because such a criterion is immediately observable by direct comparison of firms' outcomes. In fact, when products are substitutes and the parameter configuration supports multiplicity of equilibria in pure strategies, Pareto dominance allows us to conclude that (PM,PM) Pareto dominates $(\mathrm{B}, \mathrm{B})$.

Figure 1 clarifies the shapes of profit differentials in the parameter space $(\beta, d)$ in both cases of substitutability and complementarity. The different areas in the figure discriminate amongst the several outcomes of the codetermination game (Proposition 1). In particular, when products are substitutes, area A represents the region for which $(\mathrm{B}, \mathrm{B})$ is the unique Pareto inefficient SPNE of the game. This area resembles the Kraft's (1998) outcome. In fact, one can see that in the case of parity $(\beta=0.5)$ and homogeneous products $(d=1)$, B strictly dominates PM and then every firm has a unilateral incentive to do not deviate from codetermination. The area inside the red-bordered rectangle represents the set of $\beta$ and $d$ pairs relevant for codetermination, i.e. the region where

\footnotetext{
12 A Nash equilibrium is Payoff-dominant if it Pareto dominates all the other Nash equilibria in the game. It is riskdominant if it is less risky.
} 
workers have almost near-parity of the board-level employee representation. In this area, all the possible outcomes of the model may emerge depending on the degree of product differentiation. This is in line with the near-parity assumption discussed by Kraft (1998) as well as with the comparison between codetermination with near-parity and codetermination with a lower degree of employees' representation on the supervisory board studied by Gorton and Schmid (2004).

In contrast, areas B and $\mathrm{C}$ are, respectively, the regions in which multiple pure-strategy Nash equilibria exist and (PM,PM) is the unique Pareto efficient SPNE of the game. The figure shows that departing from homogeneous products ( $d$ becomes smaller than one) causes an increase in profits of both firms. Product differentiation, in fact, tend to increase firm's market power. This implies, ceteris paribus, an increase in the relative weight of firm's profits in the Nash bargaining to determine employment with unions. As firm-specific unions have the aim of increasing employment, they should not need to increase anymore the bargaining power to get their own objective. This is because the increased firm's profitability caused a larger degree of product differentiation works exactly out in the direction of the union's will. This allows us to conclude that a reduction in $\beta$ tends to reduce firm's profits under codetermination. Therefore, as long as the degree of product differentiation increases, the reduction in profits under codetermination becomes so strong that it does not make it more convenient for each firm to codetermine employment with its firm-specific union. As can be seen, in the case of near-parity (i.e., $\beta$ is around 0.5 ), $\mathrm{C}$ is the largest area as it captures the majority of combination of both parameters so that both firms find it convenient to be profit maximisers rather being bargainers with codetermination. This is of importance as the product differentiation help solving the prisoner's dilemma raised in Kraft (1998). 


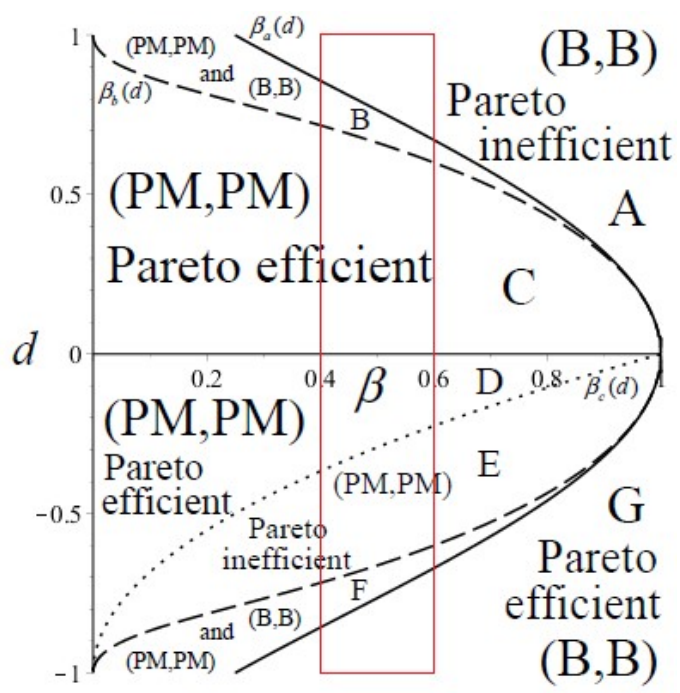

Figure 1. Codetermination and product differentiation in a quantity-setting duopoly. Profit differentials in $(\beta, d)$ space when products are substitutes $(d>0)$ and complementary $(d<0)$. The solid (resp. dashed) [resp. dotted] line represents the threshold value $\beta_{a}(d)$ (resp. $\beta_{b}(d)$ ) [resp. $\beta_{c}(d)$ ] related to profit differential $\Delta_{a}$ (resp. $\Delta_{b}$ ) [resp. $\Delta_{c}$ ]. Only in area A, the result of Kraft (1998) holds. The figure shows that when $\beta$ is close to 0.5 , it is sufficient that consumers perceive products as weakly substitutable to enter a region with multiple Nash equilibria, where PM payoff dominates B.

An example may help illustrating how the incentive to deviate from the profit maximising behaviour drops when products are differentiated. Let us assume that customers start perceiving products as differentiated. Then, the degree of product differentiation passes from $d=1$ (full substitutability or homogeneity) to an intermediate value, for instance, $d=0.5$. In addition, we consider the case of near-parity between owners and unions on employment negotiations $(\beta=0.5)$. In this case, Figure 1 clearly shows that everything can happen with regard to the outcome of the game, depending on the degree of product differentiation. Therefore, the production of the deviating firm 1 (resp. "cheating" firm 2) increases from $q_{1}=1 / 3$ to $q_{1}=1 / 2$ (resp. decreases from $q_{2}=1 / 3$ to $q_{2}=1 / 4$ ) when $d=1$, with a percentage output increase about 50 per cent and a new market share about 67 per cent instead of the previous 50 per cent (Table 1.A). By contrast, when $d=0.5$ the production of the deviating firm 1 (resp. the "cheating" firm 2) increases from $q_{1}=0.4$ to $q_{1}=0.545$ (resp. decreases from $q_{2}=0.4$ to $q_{2}=0.364$ ) with a percentage output increase of about 36.4 per cent and a new market share of about 60 per cent instead of the previous 50 per cent (Table 
1.B). The example shows that the higher the product differentiation, the lower the market share captured by the firm due to the deviation from profit maximisation to codetermination, and the lower the gain in terms of firm's profitability. It also helps clarifying the reason why as the degree of product differentiation (as perceived by customers) increases, the game from a prisoner's dilemma where the SPNE is $(\mathrm{B}, \mathrm{B})$ becomes a cooperation game where the efficient SPNE is (PM,PM). In fact, by considering near-parity of the board-level employee representation $(\beta=0.5)$ and passing from $d=1$ to $d=0.5$, we move from a situation in which PM is the dominant strategy to a situation in which B is the dominant strategy. This implies that the profitability of the firms increases in all cases (Tables 2.A and 2.B), including the strategy in which firm 1 plays PM and firm 2 plays B. This makes it convenient to deviate from B to PM when $d=0.5$ (this instead does not happen when the products are homogeneous).

\begin{tabular}{|c|c|c|}
\hline Firm 2 & PM & B \\
Firm 1 & & \\
\hline PM & $0.33,0.33$ & $0.25,0.5$ \\
\hline B & $0.5,0.25$ & $0.4,0.4$ \\
\hline
\end{tabular}

Table 1.A. Example $(d=1)$. Equilibrium values of quantities under B and PM.

\begin{tabular}{|c|c|c|}
\hline Firm 2 & PM & B \\
\hline Firm 1 & & \\
\hline PM & $0.11,0.11$ & $0.0625,0.125$ \\
\hline B & $0.125,0.0625$ & $0.08,0.08$ \\
\hline
\end{tabular}

Table 2.A. Example $(d=1)$. Payoff matrix (profits) under B and PM.

\begin{tabular}{|c|c|c|}
\hline Firm 2 & PM & B \\
\cline { 1 - 3 } Firm 1 & & \\
\hline PM & $0.4,0.4$ & $0.36,0.54$ \\
\hline B & $0.54,0.36$ & $0.5,0.5$ \\
\hline
\end{tabular}

Table 1.B. Example $(d=0.5)$. Equilibrium values of quantities under $\mathrm{B}$ and $\mathrm{PM}$. 


\begin{tabular}{|c|c|c|}
\hline Firm 2 & PM & B \\
\cline { 1 - 3 } Firm 1 & & \\
\hline PM & $0.16,0.16$ & $0.132,0.148$ \\
\hline B & $0.148,0.132$ & $0.125,0.125$ \\
\hline
\end{tabular}

Table 2.B. Example ( $d=0.5$ ). Payoff matrix (profits) under B and PM.

When customers perceive products as complementary, the behaviour of the game is quite similar to the case of substitutability. However, the welfare properties for firms of the SPNE's are different and offer an interesting economic interpretation. In fact, area $G$ is the parameter space in which $(B, B)$ is the unique Pareto efficient SPNE of the game, whereas there are multiple Nash equilibria in pure strategy when parameters belong to area F. However, there exist two other cases, namely E and D, with respect to which the unique SPNE of the game is (PM,PM) and this outcome is suboptimal and Pareto efficient, respectively. By considering negative values of $d$, an increase in the degree of product complementarity (i.e., an increase in the absolute value of $d$ ) implies that both firms may jointly increase their profitability as if they colluded in the market. Then, an increase in the relative bargaining power of unions is required to increase employment in each single firm. This, however, causes a reduction in firms' profits under codetermination allowing to gradually eliminating the incentive of being bargainers under codetermination, so that the profit maximising behaviour becomes the equilibrium outcome for a wide range of parameter values. The economic intuition behind these profitability effects is as follows. First, we note that product complementarity changes the characteristics of the competition between firms ${ }^{13}$. The effects of this change can be unambiguously observed when the union's power is very low. For instance, from Figure 1 it is easy to see that when $\beta \rightarrow 1$ the codetermined (resp. profit maximisation) case ensures higher equilibrium profits if products are complementary (resp. substitutes). This profitability reversal under product complementarity is in line with the expected effect of the strategic complementarity, according to which the larger quantity induced by the codetermination in one firm also stimulates

\footnotetext{
${ }^{13}$ In fact, note that when products pass from substitutes to complements also the Cournot competition is transformed from a game played in strategic substitutes to a game played in strategic complements, and, as a consequence, increased output may be more profitable for firms.
} 
consumers' demand addressed to (and profits of) the rival. ${ }^{14}$ However, we have shown that when products are no too much complementary this is no longer the case, as codetermination is profitreducing at equilibrium. This is because - ceteris paribus with regard to the increase of production induced by a certain level of codetermination (i.e. a certain level of $\beta$ ) - the positive effect of such an increase due to complementarity is less effective when the degree of complementarity is reduced. In other words, with a sufficiently low degree of complementarity the institution of codetermination induces an "excessive" production that more than counterbalances the positive profit-effect of the (loosely speaking) “consumption” externality. Definitely, this institution becomes profit-reducing even when products are complementary. For instance, we may see that for the sizable parametric area D in Figure 1 the possibly expected (due to the "externality" of product complementarity) positive profit-effect of a quantity shock increase (induced by codetermination), does no longer appear as the degree of complementarity is not sufficiently high.

Moreover, when (PM,PM) is the sub-optimal SPNE of the game (area E), an interesting policy consequence emerges: implementing codetermination by law Pareto dominates profit maximisation (and obviously codetermination is always consumer's welfare enhancing). This is summarised in the following result:

Result 1. Under product complementarity, codetermination rules enforced by law can remedy the welfare loss caused by the endogenous determination of the PM regime (area E).

\section{Codetermination and innovation}

This section extends the differentiated duopoly analysed in Section 2 by considering product innovation investments (R\&D expenditures) as in Kraft et al. (2011), who in turn developed the model of d'Aspremont and Jacquemin (1988) by adding Nash-bargaining on employment (codetermination) studying how codetermination affects innovativeness on firms from both

\footnotetext{
${ }^{14}$ Broadly speaking, product complementarity acts as a "consumption externality".
} 
theoretical and empirical perspectives. The theoretical model proposed by Kraft and his co-authors begins by the idea of Kraft (1998). However, different from the original contribution, Kraft et al. (2011) did not consider the endogenous outcome emerging in a game played by quantity-setting duopoly firms that have to choose whether being codetermined or profit maximisers in a context of R\&D expenditure (which is assumed not to be the subject of negotiations of firms' and unions' representatives). They indeed restricted the analysis to an exogenous comparison of firms' profits under the two strategies considered and showed, for economically meaningful values of the cost of innovation, that the bargainers' $R \& D$ innovative investment and output are both larger than that of the profit maximiser. They also found that the profit of the profit maximiser is larger than the profit of the bargainer under codetermination. To this purpose, Kraft et al. (2011) concluded that "Hence, it is quite likely that the bargaining firm has higher expenditures for $R \& D$ even if $R \& D$ is not the subject of negotiations. The reason for this is that the bargaining firm has an incentive for firm size, as long as this is connected with employment. Both process and product innovation have a positive impact on size and this determines the result." However, the fact that the codetermination will lead firms to carry out more R\&D may make sense only knowing whether B emerges as the endogenous outcome of a game played by two Cournot firms. This section aims at filling this gap by adding R\&D along the lines of Kraft et al. (2011) to the model of Section 2 and investigates whether and how the SPNE of the game is B or PM.

By turning on to the model setting, we still assume that the marginal willingness to pay of consumers for product of variety $i$ is $p_{i}=1-q_{i}-d q_{j}(i=\{1,2\}, i \neq j)$, whereas the cost function follows d'Aspremont and Jacquemin (1988) and the subsequent literature and it is given by $C_{i}=\left(w-x_{i}\right) q_{i}$, where $x_{i} \leq w$ is the cost of the innovative activity of firm $i$ (the amount of research undertake by firm $i$ ), which contributes to reduce production costs and represents the benefit of innovation. For simplicity, we ignore the spillover or externality effect produced by the amount of 
research of firm $i$ 's rival. The cost of innovation instead is given by $\gamma \frac{x_{i}^{2}}{2}$ (i.e., there are decreasing returns to $R \& D$ expenditures), where $\gamma>0$ is the efficiency parameter.

By assuming that the second order condition $\gamma>2 /(2+d)^{2}:=\bar{\gamma}(d)$ is always satisfied for any given value of $d$, the profit function of firm $i$ can be written as follows:

$$
\Pi_{i}=\left(1-q_{i}-d q_{j}-w+x_{i}\right) q_{i}-\gamma \frac{x_{i}^{2}}{2} .
$$

The Nash bargaining between firms and unions over employment takes the form:

$$
V_{i}=\left[\left(1-q_{i}-d q_{j}-w+x_{i}\right) q_{i}-\gamma \frac{x_{i}^{2}}{2}\right]^{\beta}\left(w q_{i}\right)^{1-\beta},
$$

where the control variable is $q_{i}$, as $x_{i}$ is not subject to any negotiations in line with Kraft et al. (2011). From now on, we assume that $\beta=0.5$ without loss of generality ${ }^{15}$ and concentrate on the relationship between the efficiency parameter and the degree of product differentiation in determining the outcome of the game played by firm 1 and firm 2 that have to choose between being a profit maximiser or a bargainer under codetermination in the presence of R\&D. The game is solved according to the standard backward logic.

The equilibrium values of $R \& D$ expenditure, output and profit of firm 1 and firm 2 under profit maximisation (PM) and codetermination (B) in the cases of symmetric and asymmetric behaviours are summarised in Tables 3, 4 and 5, respectively.

\begin{tabular}{|c|c|c|}
\hline Firm 2 & PM & B \\
\hline Firm 1 & $\frac{1}{\gamma(2+d)-1}, \frac{1}{\gamma(2+d)-1}$ & $\frac{3-2 \gamma(3-2 d)}{4 \gamma\left(3+\gamma d^{2}-3 \gamma\right)-3}, \frac{4[1-\gamma(2-d)]}{4 \gamma\left(3+\gamma d^{2}-3 \gamma\right)-3}$ \\
\hline B & $\frac{4[1-\gamma(2-d)]}{4 \gamma\left(3+\gamma d^{2}-3 \gamma\right)-3}, \frac{3-2 \gamma(3-2 d)}{4 \gamma\left(3+\gamma d^{2}-3 \gamma\right)-3}$ & $\frac{4}{2 \gamma(3+2 d)-3}, \frac{4}{2 \gamma(3+2 d)-3}$ \\
\hline
\end{tabular}

\footnotetext{
${ }^{15}$ We recall that "In Germany due to codetermination laws workers in large firms have nearly the same decision rights as capital owners... On the supervisory board employees have near-parity rights" (Kraft, 1998, 195) and then our assumption of parity not only simplifies algebra and allows for a clear interpretation of results but it also captures a specific characteristic of some actual economies.
} 
Table 3. Equilibrium values of R\&D expenditure of innovating quantity-setting firms in a differentiated duopoly with (B) and without (PM) codetermination.

\begin{tabular}{|c|c|c|}
\hline Firm 2 & PM & B \\
\hline Firm 1 & & \\
\hline PM & $\frac{\gamma}{\gamma(2+d)-1}, \frac{\gamma}{\gamma(2+d)-1}$ & $\frac{\gamma[3-2 \gamma(3-2 d)]}{4 \gamma\left(3+\gamma d^{2}-3 \gamma\right)-3}, \frac{4 \gamma[1-\gamma(2-d)]}{4 \gamma\left(3+\gamma d^{2}-3 \gamma\right)-3}$ \\
\hline B & $\frac{4 \gamma[1-\gamma(2-d)]}{4 \gamma\left(3+\gamma d^{2}-3 \gamma\right)-3}, \frac{\gamma[3-2 \gamma(3-2 d)]}{4 \gamma\left(3+\gamma d^{2}-3 \gamma\right)-3}$ & $\frac{4 \gamma}{2 \gamma(3+2 d)-3}, \frac{4 \gamma}{2 \gamma(3+2 d)-3}$ \\
\hline
\end{tabular}

Table 4. Equilibrium values of quantities of innovating quantity-setting firms in a differentiated duopoly with (B) and without (PM) codetermination.

\begin{tabular}{|c|c|c|}
\hline Firm2 & PM & B \\
\hline PM & $\frac{\gamma(2 \gamma-1)}{[\gamma(2+d)-1]^{2}}, \frac{\gamma(2 \gamma-1)}{[\gamma(2+d)-1]^{2}}$ & $\frac{\gamma(2 \gamma-1)[2 \gamma(3+2 d)-3]^{2}}{2\left[4 \gamma\left(3+\gamma d^{2}-3 \gamma\right)-3\right]^{2}}$, \\
\hline B & $\frac{\gamma(2 \gamma-1)\left(8 d^{2} \gamma^{2}-32 d \gamma^{2}+16 d \gamma+32 \gamma^{2}-34 \gamma+9\right)}{2\left[4 \gamma\left(3+\gamma d^{2}-3 \gamma\right)-3\right]^{2}}$ & $\frac{\gamma(2 \gamma-1)\left(8 d^{2} \gamma^{2}-32 d \gamma^{2}+16 d \gamma+32 \gamma^{2}-34 \gamma+9\right)}{2\left[4 \gamma\left(3+\gamma d^{2}-3 \gamma\right)-3\right]^{2}}$ \\
& $\frac{\gamma(2 \gamma-1)[2 \gamma(3+2 d)-3]^{2}}{2\left[4 \gamma\left(3+\gamma d^{2}-3 \gamma\right)-3\right]^{2}}$ & $\frac{4 \gamma(2 \gamma-1)}{[2 \gamma(3+2 d)-3]^{2}}, \frac{4 \gamma(2 \gamma-1)}{[2 \gamma(3+2 d)-3]^{2}}$ \\
\hline
\end{tabular}

Table 5. Payoff matrix: profits of innovating quantity-setting firms in a differentiated duopoly with (B) and without (PM) codetermination.

In order to guarantee that all the entries of Tables 3-5 are positive, it should hold that $\gamma>1 / 2$

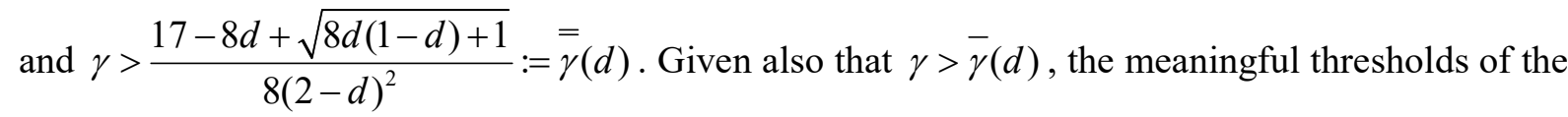
efficiency parameter are the following: $\gamma>\bar{\gamma}(d)$ for any $-1<d \leq 0$ and $\gamma>\bar{\gamma}(d)$ for any $0<d<1$. These two inequalities are assumed to be fulfilled. Economic feasibility is represented by areas above the red region (product complementarity) and blue region (product substitutability) in Figure 2. Now, define $d_{a}^{+}(\gamma)$ (this holds for positive values of $d$ ) and $d_{a}^{-}(\gamma)$ (this holds for negative values of $d$ ) be two threshold values of $d$ such that $\Delta_{a}=\Pi_{i}^{B / P M}-\Pi_{i}^{P M / P M}=0$ (note that closed form expressions for $d_{a}^{+}(\gamma)$ and $d_{a}^{-}(\gamma)$ do not exist). In addition, let $d_{b}(\gamma):=\frac{(2 \gamma-1) \sqrt{6-3 \sqrt{2}}}{4 \gamma}$ and 
$d_{c}(\gamma):=\frac{(2 \gamma-1)(\sqrt{2} / 2-1)}{2 \gamma}$ be two threshold values of $d$ such that $\Delta_{b}=\Pi_{i}^{P M / B}-\Pi_{i}^{B / B}=0$ and $\Delta_{c}=\Pi_{i}^{P M / P M}-\Pi_{i}^{B / B}=0$, respectively. Then, the following proposition holds.

Proposition 2. [Codetermination and innovation]. (a) (Product substitutability). (1) If $1>d>d_{a}^{+}(\gamma)$ then $(\mathrm{B}, \mathrm{B})$ is the unique Pareto inefficient SPNE of the game (prisoner's dilemma). (2) If $d_{a}^{+}(\gamma)>d>d_{b}(\gamma)$ then there exist two pure-strategy Nash equilibria given by (B,B) and (PM,PM), and PM payoff dominates B (coordination game). (3) If $d_{b}(\gamma)>d>0$ then (PM,PM) is the unique Pareto efficient SPNE of the game (cooperation game).

(b) (Product complementarity). (1) If $d_{c}(\gamma)<d<0$ then (PM,PM) is the unique Pareto efficient SPNE of the game (cooperation game). (2) If $d_{b}(\gamma)<d<d_{c}(\gamma)$ then (PM,PM) is the unique Pareto inefficient SPNE of the game (prisoner's dilemma). (3) If $d_{a}^{-}(\gamma)<d<d_{b}(\gamma)$ then there exist two pure-strategy Nash equilibria given by $(\mathrm{B}, \mathrm{B})$ and $(\mathrm{PM}, \mathrm{PM})$, and $\mathrm{B}$ payoff dominates $\mathrm{PM}$ (coordination game). (4) If $-1<d<d_{a}^{-}(\gamma)$ then $(\mathrm{B}, \mathrm{B})$ is the unique Pareto efficient SPNE of the game (cooperation game).

Proof. The profit differentials are the following:

$$
\begin{gathered}
\Delta_{a}=\frac{(1-w)^{2} \gamma^{2}(2 \gamma-1)\left[-8 \gamma^{3} d^{4}+\left(32 \gamma^{2}-34 \gamma+9\right) \gamma d^{2}+2\left(-4 \gamma^{2}+4 \gamma-1\right) d-16 \gamma^{3}+24 \gamma^{2}-12 \gamma+2\right]}{2\left[4 \gamma\left(3+\gamma d^{2}-3 \gamma\right)-3\right]^{2}[\gamma(2+d)-1]^{2}}, \\
\Delta_{b}=\frac{(1-w)^{2} \gamma(2 \gamma-1)\left[128 \gamma^{4} d^{4}+96\left(-4 \gamma^{2}+4 \gamma-1\right) \gamma^{2} d^{2}+144 \gamma^{4}-288 \gamma^{3}+216 \gamma^{2}-72 \gamma+9\right]}{2\left[4 \gamma\left(3+\gamma d^{2}-3 \gamma\right)-3\right]^{2}[2 \gamma(3+2 d)-3]^{2}},
\end{gathered}
$$

and

$$
\Delta_{c}=\frac{(1-w)^{2} \gamma(2 \gamma-1)\left[8 \gamma^{2} d^{2}+16 \gamma^{2} d-8 \gamma d+4 \gamma^{2}-4 \gamma+1\right]}{2[\gamma(2+d)-1]^{2}[2 \gamma(3+2 d)-3]^{2}} .
$$


The sign of $\Delta_{a}, \Delta_{b}$ and $\Delta_{c}$ change depending on the relative position of $\gamma$ and $d$. In the case of product substitutability, $\Delta_{c}>0$ for any (meaningful values of) $\gamma$. In addition, (1) if $1>d>d_{a}^{+}(\gamma)$ then $\Delta_{a}>0$ and $\Delta_{b}<0$, (2) if $d_{a}^{+}(\gamma)>d>d_{b}(\gamma)$ then $\Delta_{a}<0$ and $\Delta_{b}<0$, (3) if $d_{b}(\gamma)>d>0$ then $\Delta_{a}<0$ and $\Delta_{b}>0$. Therefore, point (a) follows. In the case of product complementarity, we have that (1) if $d_{c}(\gamma)<d<0$ then $\Delta_{a}<0, \Delta_{b}>0$ and $\Delta_{c}>0$, (2) if $d_{b}(\gamma)<d<d_{c}(\gamma)$ then $\Delta_{a}<0, \Delta_{b}>0$ and $\Delta_{c}<0$, (3) if $d_{a}^{-}(\gamma)<d<d_{b}(\gamma)$ then $\Delta_{a}<0, \Delta_{b}<0$ and $\Delta_{c}<0,(4)$ if $-1<d<d_{a}^{-}(\gamma)$ then $\Delta_{a}>0$, $\Delta_{b}<0$ and $\Delta_{c}<0$. Therefore, point (b) follows. Q.E.D.

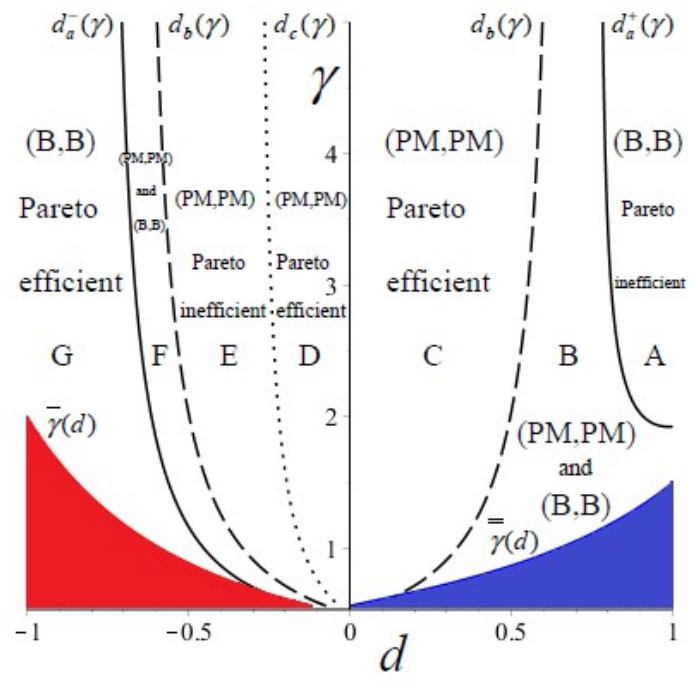

Figure 2. Codetermination and product differentiation in a quantity-setting duopoly with R\&D. Profit differentials in $(d, \gamma)$ space when products are substitutes $(d>0)$ and complements $(d<0)$. The solid (resp. dashed) [resp. dotted] line represents the threshold value $d_{a}(\gamma)\left(\operatorname{resp} . d_{b}(\gamma)\right)$ [resp. $\left.d_{c}(\gamma)\right]$ related to $\Delta_{a}$ (resp. $\left.\Delta_{b}\right)\left[\right.$ resp. $\left.\Delta_{c}\right]$. The figure is computed for $\beta=0.5$. The red and blue areas are unfeasible regions. The thresholds $\bar{\gamma}(d)$ and $\bar{\gamma}(d)$ represent the upper bounds of these areas. The lower bound of $\gamma$ is 0.5625 .

Results of Proposition 2 (codetermination and innovation) are in line with the results of Proposition 1 (codetermination and product differentiation). In fact, the amount of research each firm undertakes works out in the direction of increasing the willingness of consumers' of perceiving products as being highly differentiated. This in turn causes (ceteris paribus with regard to the relative bargaining power of unions) an increase in both the quantity produced and sold by the firms 
and the corresponding profits in the case of profit maximisation by favouring the emergence of (PM,PM) as the endogenous outcome of the game. In addition, the prisoner's dilemma may be solved by increasing the degree of product differentiation. Indeed, $(B, B)$ emerges as the inefficient SPNE of the game only when product are highly substitutable and the degree of competition in the product market is larger.

Although the bargainers' $R \& D$ innovative investment and output are both larger than the corresponding values of the profit maximiser, this make sense only whether $(\mathrm{B}, \mathrm{B})$ is the endogenous outcome of the game and this holds only in the case of (high) product substitutability. Otherwise, firms have an incentive to be profit maximisers and doing a smaller amount of research. These results - extending Kraft (2011) to the determination of the SPNE of the game - support the view that with heterogeneous products codetermination can emerge only with an enforcement by the lawmaker also when firms undertake R\&D activities.

Finally, some considerations about the robustness of the present results to the cases of labour market institutions different from the co-determination are in order here. In fact, by following the spirit of a reviewer's comment, who suggested extending the analysis to a sequential game where workers' and employers' representatives are subject to the rules of institutions different from codetermination, we studied a game to compare a situation where each player (firm) had to choose between three alternatives: (1) to be a profit maximiser (PM); (2) bargaining only over the wage with its own firm-specific union ${ }^{16}$ as dictated by the right-to-manage model (RTM); (3) bargaining over both the wage and employment with its own firm-specific union by following the (sequential) efficient bargaining hypothesis (SEB). The RTM institution follows Naylor (2002), Correa-López and Naylor (2004) and Fanti and Buccella (2017) and implies that once the wage is fixed by the two parties that have to simultaneously bargain with conflicting interests at first stage of the game, each

\footnotetext{
${ }^{16}$ By passing, we note that comparing institutions where the wage is determined at the firm level with an institution where instead the wage was bargained at a centralised level, as suggested by an anonymous reviewer, is not an easy task, especially if one wants to study the asymmetric cases. This is essentially because of the endogeneity of the threat point that should be set in the Nash product function of the national or industry-wide union when it bargains separately with each single firm, thus making the endogenous comparison of these institutions difficult from an analytical point of view in this kind of models.
} 
firm has the right to set its own employment at the second stage of the game. Differently, the SEB institution follows the contributions of Manning (1987a, 1987b) and Fanti and Buccella (2017). It implies that (firm-specific) workers' representatives and employers' representatives bargain over the wage at the first stage of the game and (by taking into account this choice) they also bargain over employment at the second stage of the game. By applying the standard backword logic, the unique efficient SPNE emerging in the case of product substitutability as long as $\beta$ and $d$ vary is (PM,PM), which continues to hold also in the case of product complementarity for a wider set of parameter values. ${ }^{17}$ We note that neither RTM nor SEB do never emerge in this context as an endogenous outcome, so confirming the spirit of our results under co-determination in the sense that no labour market institutions (different from a competitive labour market) may appear as a Nash equilibrium. $^{18}$

\section{Conclusions}

Codetermination is a practice useful to reduce conflicts amongst ownership and labour institutions within a firm. It also helps increasing the bargaining power of workers (through the behaviour of firm-specific unions) at the expense of owners' representatives by means of ad-hoc laws. The codetermination legislation can also represent a public policy instrument useful to correct market failures. In this article, we revisited first the codetermined duopoly of Kraft (1998), where firms were engaged in a Cournot competition game with homogeneous products and then Kraft et al. (2011), where firms were engaged in a Cournot competition game with differentiated products (horizontal differentiation) and R\&D activities. In the first context, Kraft (1998) showed that the profit-maximising firm gets smaller profits than the codetermined rival does. Thus, the profit

\footnotetext{
${ }^{17}$ For the sake of precision, we also report the special case that when products are perceived as (almost) perfect complements $(d \rightarrow-1)$ and the bargaining power of unions is large enough $(\beta \rightarrow 0)$, the game first becomes a prisoner's dilemma as (PM,PM) is the unique inefficient SPNE, then it will result to be a coordination game as (SEB,SEB) and (PM,PM) are multiple pure strategies Nash equilibria (where SEB payoff dominates PM).

${ }^{18} \mathrm{We}$ chose to do not present a formal treatment of these cases for a twofold reason. First, these institutions are different from codetermination (where only the employment is the subject of negotiations between decentralised unions and owners at the "local" level, the wage being bargained at the national or industry-wide level). Second, the results are those expected in the established literature about unionised oligopolies.
} 
maximiser has an incentive to become a bargainer with codetermination. Later, Kraft et al. (2011) found that it is quite likely that the bargaining firm has higher expenditures for R\&D, without further extending the theoretical investigation. This work revisited these two contributions in a twofold direction. (1) It included horizontal product differentiation in Kraft's (1998) framework. (2) It investigated the SPNE outcomes of the model of Kraft et al. (2011). The main conclusion is that product substitutability of complementarity allowed eliminating the incentive to deviate from the profit-maximising strategy, so that codetermination emerges as a market outcome only when products are highly substitutable, irrespective of R\&D investments.

Definitely, under product differentiation codetermination is harmful for firms ${ }^{19}$ and does not emerge as an industry equilibrium. Such a labour market institution - which would be preferred by consumers - may emerge only through an appropriate law in several contexts. The results of this article contribute to explain the reasons why codetermination does not emerge as a market outcome (Nash equilibrium) whereas existing only in countries where specific laws govern its activities.

Finally, we note that the study of the effects of codetermination in different economic contexts is so far largely unexplored and therefore future research on this issue may be promising. Especially, testing whether codetermination can emerge in cases of managerial incentive contracts - such as sales delegation, market share and relative profits - or under network goods may be of interest in the industrial organisation. This may be applied also to the case of mixed duopolies as in the recent work of Nakamura (2015).

Acknowledgements The authors gratefully acknowledge conference participants at SIE 2015 held at Parthenope University of Naples (Italy) for comments on an earlier draft. The authors also thank two anonymous reviewers for helpful and valuable comments and suggestions that have contributed to improve the work. The usual disclaimer applies.

Conflict of Interest The authors declare that they have no conflict of interest.

\footnotetext{
${ }^{19}$ This may even be true in the case of product complementarity, notwithstanding the latter implies that increased output by itself is no longer profit-reducing at equilibrium.
} 


\section{References}

Baums, T., Frick, B., 1998. Co-determination in Germany: the impact of court decisions on the market value of firms. Economic Analysis 1, 143-161.

Booth, A.L., 1995. The Economics of Trade Unions. Cambridge University Press.

Cable, J.R., FitzRoy, F.R. 1980. Productive efficiency, incentives and employee participation: some preliminary results for West Germany. Kyklos 33, 100-121.

Correa-López, M., Naylor, R.A., 2004. The Cournot-Bertrand profit differential: a reversal result in a differentiated duopoly with wage bargaining. European Economic Review 48, 681-696.

d'Aspremont, C., Jacquemin, A., 1988. Cooperative and noncooperative R\&D in duopoly with spillovers. American Economic Review 78, 1133-1137.

Fanti, L., Buccella, D., 2017. Timing and the selection of the bargaining agenda. In: Oligopoly, institutions and firms' performance, Fanti, L., ed., Pisa University Press, Italy.

Fanti, L., Gori, L., 2012. The codetermined firm in a Cournot duopoly: a stability analysis. Economic Modelling 29, 1242-1247.

Fanti, L., Gori, L., Sodini, M., 2017. The bargaining-sales-delegation game. Managerial and Decision Economics 38, 857-889.

FitzRoy, F.R., Kraft, K., 1993. Economic effects of codetermination. Scandinavian Journal of Economics 95, 365-375.

FitzRoy, F.R., Kraft, K., 2005. Co-determination, efficiency and productivity. British Journal of Industrial Relations 43, 233-247.

Gorton, G., Schmid, F.A., 2004. Capital, labor, and the firm: a study of German codetermination. Journal of the European Economic Association 2, 863-905.

Granero, L.M., 2006. Codetermination, R\&D, and employment. Journal of Institutional and Theoretical Economics 162, 309-328.

Gürtler, O., Höffler, F., 2015. Monitoring of workers and product market competition: the role of works councils. Economic Inquiry 53, 1366-1379.

Kraft, K., 1998. The codetermined firm in oligopoly. Economics Letters 61, 195-201.

Kraft, K., 2001. Codetermination as a strategic advantage? International Journal of Industrial Organization 19, 543-566.

Kraft, K., Stank, J., Dewenter, R., 2011. Co-determination and innovation. Cambridge Journal of Economics 35, 145-172.

Manning, A., 1987. An integration of trade union models in a sequential bargaining framework. Economic Journal 97, 121-139. 
Manning, A., 1987. Collective bargaining institutions and efficiency: an application of a sequential bargaining model. European Economic Review 31, 168-176.

McCain, R.A., 1980. A theory of codetermination. Journal of Economics 1-2, 65-90.

Nakamura, Y., 2015. Endogenous choice of strategic incentives in a mixed duopoly with a new managerial delegation contract for the public firm. International Review of Economics and Finance $35,262-277$.

Naylor, R.A., 2002. Industry profits and competition under bilateral oligopoly. Economics Letters $77,169-175$.

Schulten, T., Zagelmeyer, S., 1998. Board-level employee representation in Europe. Eurofound. Available at https://www.eurofound.europa.eu/printpdf/observatories/eurwork/comparativeinformation/board-level-employee-representation-in-europe.

Singh, N., Vives, X., 1984. Price and quantity competition in a differentiated duopoly. RAND Journal of Economics 15, 546-554.

Waddington, J., Conchon, A., 2016. Board Level Employee Representation in Europe. Priorities, Power and Articulation. New York and London: Routledge. 